\title{
Calculation of engine power for a tractor of traction class 1.4 with a technological module
}

\author{
Maksim Sidorov ${ }^{1}$, Alexander Lavrov ${ }^{2 *}$, Victor Voronin ${ }^{3}$, and Anastasia Sidorova ${ }^{4}$ \\ ${ }^{1}$ Kaluga branch of the RSAU-Moscow Agricultural Academy named after A.K. Timiryazeva, \\ Vishnevskogo, 27, Kaluga, 248007, Russian Federation \\ ${ }^{2}$ Federal Scientific Agro-Engineering Center VIM, 1 Institutsky proezd, 5, Moscow, 109428, Russia \\ ${ }^{3}$ Bryansk State Agrarian University, Sovetskaya, 2a, Kokino, Bryansk region, 243365, Russian \\ Federation \\ ${ }^{4}$ Kaluga branch of the Moscow State Technical University N.E. Bauman, Bazhenova, 2, Kaluga, \\ 248000, Russian Federation
}

\begin{abstract}
The technological provision of peasant farms is characterized by a deficit in their fleet of tractors of classes 2, 3. As a promising direction for solving this problem, it is proposed to develop a technological module that allows increasing the versatility of class 1.4 tractors by transferring them to a higher traction class. To calculate the rated power of the engine of a tractor of class 1.4, when operating it with a technological module, a method is proposed that takes into account the design features of the modular construction of a machine-tractor unit.
\end{abstract}

\section{Introduction}

The efficiency of the development of peasant (farmer) households is largely determined by the promising direction of production activities, natural and climatic conditions, rational organization of production and equipment. Despite the small cultivated area, the optimal type for farms should include tractors of traction classes 1.4; 2 and 3 [1].

However, due to the low paying capacity of the economy, as a rule, 1-2 tractors of class 1.4 are used. At the same time, it is important for the owner of the farm to independently perform the maximum possible amount of work, since the involvement of agricultural machinery and labor resources is usually much more expensive, and sometimes there is no such possibility at all. In these conditions, from the point of view of the owner, it is advisable to have a device that increases the versatility of existing tractors, transferring them to a higher adjacent traction class, while the device should have an affordable price.

To solve this problem, on the basis of the existing element base, a technological module (TM) has been developed, which makes it possible to transfer a serially produced tractor of class 1.4 (Belarus 82.1) to traction class 2 [2].

A general view of an agricultural tractor with TM is shown in Figure 1.

\footnotetext{
* Corresponding author: vimlavrov@mail.ru
} 




Fig. 1 Technological spaces on a tractor with a technological module: 1 - technological spaces; 2 front hitch; 3 - tractor; 4 - technological module

The main agrotechnical requirements for TM were developed with the participation of a creative team of scientists at the Federal Scientific Agro engineering Center VIM. These requirements are based on the available scientific and technical groundwork and the results of the analysis of promising agricultural technologies [3-5].

The composition and construction study of the TM, including the adaptation of the TM to agrotechnical requirements and mass-produced Belarus 82.1 tractors, were carried out at the Kaluga facility of Moscow State Technical University named after N.E. Bauman by a group of scientists and designers with experience in similar developments [6-9].

For the most efficient operation of a machine-tractor unit (MTA) built on the basis of a tractor and TM, it is necessary to calculate the power of the tractor engine, taking into account the design features of the modular power-technological unit (MPU).

The research aim was to calculate the nominal operating power of the engine for a tractor with a technological module according to the traditional and improved methods [7, 10].

\section{Materials and methods}

It is customary to calculate the rated operating power of the tractor engine of the traction concept using the formula:

$$
N_{n . e f .}=\frac{\left(P_{\text {tr. } n}+P_{f}\right) v_{\text {trac. }}}{\eta_{\text {trac }}\left(1-\delta_{n}\right)}
$$

где $P_{t r . n}$ - value of the nominal tractive effort of the tractor, $\mathrm{kN} ; P_{f}$ - rolling resistance force of the tractor, $\mathrm{kN} ; v_{\text {trac.n }}$ - actual motion speed of the tractor at nominal tractive effort, $\mathrm{m} / \mathrm{s} ; \eta_{\text {trac }}-$ mechanical efficiency factor of tractor transmission; $\delta_{n}$ - acceptable slip value.

With a modular picking scheme for a tractor with a technological module, the modular power unit has a 6K6 wheel arrangement. Therefore, when calculating the traction of such tractors, it is necessary to take into account a number of additional factors that affect the accuracy of calculating the rated operating power of the engine.

At first, the traction and coupling properties of the tractor depend on the number of driving axles. In addition to the fact that with all driving wheels, due to traction, the full weight of the tractor is realized and the weight utilization factor $\varphi_{\text {cr }}$ increases, the effect of reducing rolling resistance (decreasing coefficient $f_{\mathrm{k}}$ ) and increasing adhesion (coefficient increasing the first bridge fig. 2. 


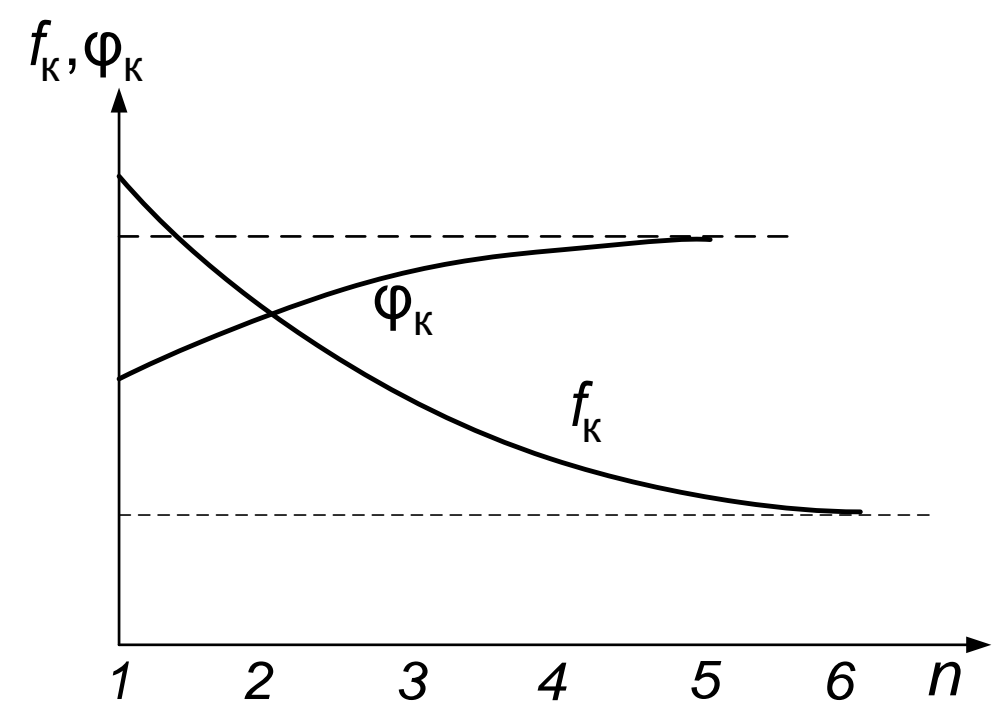

Fig. 2. Dependence of the change in $\varphi_{\mathrm{cr}}$ and $f_{k}$ on the number of passes $n$ of the wheel along one track of the deformable surface

At the second, slipping of wheels $\delta$ along individual axes is not the same and depends on the structurally specified kinematic discrepancy in their drive (coefficient $k_{\mathrm{n}}$ ), and in equation (1) only one wheel slip is used - the rear axle of the tractor.

At the third, the efficiency factor of the MPU 6K6 three-axle transmission $\eta_{\text {tr }}$ can be determined by calculation only as the total of the efficiency factors of three transmission branches: to drive the front and rear wheels of the tractor separately and to drive the TM wheels separately. The power losses in each transmission branch depend on two factors: on the mechanical efficiency $\left(\eta_{\mathrm{tr} 1}, \eta_{\mathrm{tr} 2}, \eta_{\mathrm{tr} 3}\right)$ and on the share of engine power transmitted through this transmission branch and taken into account by the power transfer coefficient $\mathrm{k}_{\mathrm{N} 1}, \mathrm{k}_{\mathrm{N} 2}, \mathrm{k}_{\mathrm{N} 3}[10]$.

Considering the above, the nominal operational power of the engine will be determined as the total of the powers consumed by a separate axle - front, rear and TM

$$
N_{\text {n.o.MPU }}=N_{\text {n.o.fr }}+N_{\text {n.o.r }}+N_{\text {n.o.TM }}
$$

где $N_{\text {n.o.мРU }}$ - engine power of modular power unit; $N_{\text {n.o.fr }}$ - engine power to drive the wheels of the front axle; $N_{\text {n.o.r }}$ - engine power to drive the wheels of the rear axle; $N_{\text {n.o.TM }}-$ engine power to drive the TM wheels.

The traction calculation is carried out with the assumption that all driving axles are blocked. This does not take into account the parasitic power spent on the sliding of the lagging wheels when the tractor is operating with a low traction load.

$$
P_{\text {cr.MPU }}=P_{c r . f r .}+P_{c r . r}+P_{c r . T M}
$$

где $P_{c r . f r}, P_{c r . r}, P_{c r . T M}-$ value of the traction force of the front and rear axles of the tractor and $\mathrm{TM}$, respectively, $\mathrm{kN}$.

Similarly, let us assume that the rolling resistance force of the tractor and the MPU is equal to the total of the rolling resistance forces of the axles of the tractor or MPU. Then for a tractor with TM

$$
P_{f . M P U}=P_{f . f r .}+P_{f . r .}+P_{f . T M}
$$


где $P_{f . f r}, P_{f . r .}, P_{f . \text { тм. }}-$ rolling resistance force of the wheels of the front, rear axles of the tractor and TM, respectively, $\mathrm{kN}$.

Adding equations (3) and (4) we get:

$$
P_{c r . M P U}+P_{f . M P U}=\left(P_{c r . f r .}+P_{f . f r .}\right)+\left(P_{c r . r}+P_{f . r .}\right)+\left(P_{c r . T M}+P_{f . T M .}\right)
$$

The left side of equation (5) is the part of the numerator of expression (1), enclosed in a parenthesis. Since the average forward speed of all driving axles is the same, the tractive power of the tractor will be equal to the sum of the powers realized by each driving axle of the MPU:

$$
\begin{gathered}
\left(P_{\text {cr.MPU }}+P_{f . M P U}\right) v_{\text {trac. }}= \\
=\left(P_{\text {cr.fr. }}+P_{f . f r .}\right) v_{\text {trac. }}+\left(P_{\text {cr. } .}+P_{\text {f.r. }}\right) v_{\text {trac. }}+\left(P_{\text {cr.TM }}+P_{f . T M .}\right) v_{\text {trac }} .
\end{gathered}
$$

Multiply and divide each term of equation (6) by the denominator of equation (1), taking into account its slipping and drive efficiency factor inherent in each bridge:

$$
\begin{aligned}
& \frac{\left(P_{\text {cr.MPU }}+P_{f . M P U}\right) v_{\text {trac. }}}{\eta_{\text {trans.MPU. }}\left(1-\delta_{n}\right)} \eta_{\text {trans.MPU. }}\left(1-\delta_{n}\right)=\frac{\left(P_{\text {cr.fr. }}+P_{f . f r .}\right) v_{\text {trac. }}}{\eta_{\text {tr.1. }}\left(1-\delta_{n . f r .}\right)} \eta_{t r .1 .}\left(1-\delta_{n . f r .}\right)+ \\
& \frac{\left(P_{\text {cr.r. }}+P_{\text {f.r. }}\right) v_{\text {trac. }}}{\eta_{\text {tr. } .2 .}\left(1-\delta_{\text {n.r. }}\right)} \eta_{t r .2 .}\left(1-\delta_{\text {n.r. }}\right)+\frac{\left(P_{\text {cr.TM }}+P_{f . T M .}\right) v_{\text {trac. }}}{\eta_{T M .}\left(1-\delta_{\text {n.TM. }}\right)} \eta_{T M .}\left(1-\delta_{\text {n.TM. }}\right)
\end{aligned}
$$

$$
\begin{aligned}
& \text { Here, } \frac{\left(P_{\text {cr.MPU }}+P_{f . M P U}\right) v_{\text {trac. }}}{\eta_{\text {trans.MPU. }}\left(1-\delta_{n}\right)}=N_{\text {n.e.MPU }} ; \frac{\left(P_{\text {cr.fr. }}+P_{f . f r .}\right) v_{\text {trac. }}}{\eta_{\text {tr.1. }}\left(1-\delta_{\text {n.fr. }}\right)}=N_{\text {n.e.fr. }} ; \\
& \frac{\left(P_{\text {cr. } . r}+P_{f . r .}\right) v_{\text {trac. }}}{\eta_{\text {tr. } .2 .}\left(1-\delta_{\text {n.r. }}\right)} \eta_{\text {tr. } 2 .}=N_{\text {n.e.r. }} ; \frac{\left(P_{\text {cr.TM }}+P_{\text {f.TM. }}\right) v_{\text {trac. }}}{\eta_{\text {TM. }}\left(1-\delta_{\text {n.TM. }}\right)} \eta_{T M .}=N_{\text {n.e.TM }}
\end{aligned}
$$

where $N_{\text {n.e.MPU }} \quad$ engine power of modular power-technological unit; $N_{\text {n.e.fr, }}, N_{\text {n.e.r. }}, N_{\text {n.e.TM }}-$ effective engine power consumed to drive the front and rear axles of the tractor and drive active wheels TM; $\eta_{\mathrm{tr} 1}, \eta_{\mathrm{tr} 2}, \eta_{\mathrm{TM}}-$ mechanical efficiency factor of the transmission branch from the engine to the front, rear axles of the tractor and to the TM; $\delta_{\kappa}$, - acceptable slip value on stubbled stubble grain wheels of the rear axle of the tractor; $\delta_{n . r .}, \delta_{n . T M}$ - slipping of the wheels of the front axle and TM, respectively, taking into account the kinematic discrepancy in their drive.

Taking into account (8), equitation (7) can be written in the following form:

$$
\begin{gathered}
N_{\text {n.e.MPU }} \eta_{\text {trans.MPU. }}\left(1-\delta_{n}\right)=N_{\text {n.e.fr. }} \eta_{\text {tr.1. }}\left(1-\delta_{\text {n.fr. }}\right)+N_{\text {n.e.r. }} \eta_{\text {tr. } 2 .}\left(1-\delta_{n . r .}\right)+ \\
N_{\text {n.e.TM }} \eta_{\text {TM. }}\left(1-\delta_{n . T M .}\right)
\end{gathered}
$$

Dividing the left and right sides of equation (9) by Nn.e, we get:

$$
\eta_{\text {trans.MPU. }}\left(1-\delta_{n}\right)=\eta_{\text {tr.1. }}\left(\begin{array}{c}
\left.1-\delta_{n . f r .}\right) k_{N 1 M} \\
\left.\delta_{n . T M .}\right) k_{N 3 M}
\end{array}+\eta_{\text {tr.2. }}\left(1-\delta_{n . r .}\right) k_{N 2 M}+\eta_{\text {tr.3. }}(1-\right.
$$

where $\eta_{\text {trans.MPU. }}$ - efficiency factor of MPU transmission; $\eta_{t r .1,}, \eta_{t r .2 .}, \eta_{T M .}$ - efficiency factors of the drive of the front, rear axle of the tractor and TM; $k_{N 1 M}, k_{N 2 M}, k_{N 3 M}-$ coefficients of power transfer to the drive of the front and rear wheels of the tractor (or EM) and TM wheels as part of the MPU, taking into account the share of power transmitted through the $\mathrm{j}$-th bridge for a tractor with TM:

$$
k_{N 1 M}=\frac{N_{\text {n.e.fr. }}}{N_{\text {n.e.MPU }}}, k_{N 2 M}=\frac{N_{\text {n.e.r. }}}{N_{\text {n.e.MPU }}}, k_{N 3 M}=\frac{N_{\text {n.e.TM }}}{N_{\text {n.e.MPU }}},
$$

To calculate the power transfer coefficients, equations (8) are used.

Mandatory in determining the power transmission coefficients is the condition 


$$
\sum_{\mathrm{j}=1}^{N} k_{\mathrm{Nj}}=1
$$

которое получается из равенства

$$
N_{\text {n.e.tr. }}=\sum_{j=1}^{N} N_{\text {n.e.j }} \text {, }
$$

where $N_{\text {n.e.j }}$ is the fraction of the effective engine power transmitted separately to the j-th bridge.

Then for a tractor with TM:

$$
1=k_{\mathrm{N} 1 \mathrm{M}}+k_{\mathrm{N} 2 \mathrm{M}}+k_{\mathrm{N} 3 \mathrm{M}},
$$

Thus, the denominator of expression (1) should be calculated as the product of the mechanical efficiency of the transmission $\eta_{\text {tr }}$ and the slipping efficiency factor $\left(1-\delta_{n}\right)$, taking into account the share of power transmitted through the $\mathrm{j}$-th bridge.

$$
\eta_{t r .}\left(1-\delta_{n}\right)=\sum_{j=1}^{N} \eta_{t r . j .} k_{N j}\left(1-\delta_{n . j}\right),
$$

and equitation (1) in general form contains in the numerator the total of traction forces and rolling resistance forces of the driving axles, and in the denominator - the total of mechanical power losses in the transmission and losses on slipping

$$
N_{n . e .}=\frac{\sum_{j=1}^{N}\left(P_{c r . j .}+P_{f . j . j}\right) v_{t r a c . n}}{\sum_{j=1}^{N} \eta_{t r . j .} k_{N j}\left(1-\delta_{n . j}\right)}
$$

где $k_{N j}$ - power transfer factor that takes into account the fraction of power transmitted through the j-th bridge; $\eta_{t r . j .}$ - mechanical efficiency factor of a separate transmission branch; $\left(1-\delta_{n . j}\right)$ - efficiency factor of slipping of the j-th bridge.

A method is proposed for determining the total engine power, realized due to the thrust force, taking into account a different number of driving axles and a transport and technological module.

\section{Results and discussions}

Calculate, according to the proposed method, the engine power of tractors of the upper traction class with a technological module during the transition from the lower to the upper traction class using the example of a tractor of traction class 1.4 .

The nominal operating power of the tractor of class 1.4 engine for a tractor of the upper class based on a tractor of class 1.4 with TM is determined according to (12):

$$
N_{\text {n.e.MPU. }}=\frac{(20,00+6,07) \cdot 2,50}{0,77}=84,66 \mathrm{~kW} .
$$

The nominal operating power of the tractor of class 1.4 engine for a tractor of the upper class based on a tractor of class 1.4 with TM will be determined according to the traditional calculation method (1), but taking into account the share of engine power realized through individual axles, since otherwise the transmission efficiency cannot be determined:

$$
N_{\text {n.e.MPU. }}=\frac{(20,00+6,07) \cdot 2,50}{0,86 \cdot(1-0,14)}=92,47 \mathrm{~kW}
$$

The results of calculating the engine power of wheeled tractors in various configurations are shown in Table 1. 
Table 1. The results of calculating the operational power of a wheel tractor of class 1.4 in the basic configuration and with TM

\begin{tabular}{|c|c|c|c|c|c|c|}
\hline \multirow[b]{3}{*}{$\begin{array}{c}\text { Versio } \\
\mathrm{n}\end{array}$} & \multicolumn{6}{|c|}{ Indicators } \\
\hline & \multirow[b]{2}{*}{$\begin{array}{l}\text { Nominal } \\
\text { tractive } \\
\text { effort, kN }\end{array}$} & \multirow[b]{2}{*}{$\begin{array}{l}\text { Tractio } \\
\text { n class }\end{array}$} & \multicolumn{2}{|c|}{$\begin{array}{c}\text { Power } \\
\text { engine, } \mathrm{kW}\end{array}$} & \multirow{2}{*}{$\begin{array}{c}\text { Energy } \\
\text { saturation of } \\
\text { MPU, } \\
\mathrm{kW} / \mathrm{kN}\end{array}$} & \multirow{2}{*}{$\begin{array}{c}\text { Operating } \\
\text { power of } \\
\text { the tractor, } \\
\mathrm{kW} \text {, } \\
\text { actual } \\
\text { MTZ-82 } \\
\text { MTZ - } \\
1221 \\
\text { (cl. } 1.4 \text {, } \\
2.0)\end{array}$} \\
\hline & & & $\begin{array}{c}\text { proposed } \\
\text { method }\end{array}$ & $\begin{array}{l}\text { traditional } \\
\text { technique }\end{array}$ & & \\
\hline Basic & 14 & 1,4 & 59,63 & 62,23 & 1,59 & 58,84 \\
\hline $\begin{array}{l}\text { With } \\
\text { TM }\end{array}$ & 20 & 2 & 84,66 & 92,47 & 1,64 & 95,6 \\
\hline
\end{tabular}

The calculation results (table 1) show that when a tractor is equipped with a TM, there is an excess of power when calculating according to the traditional method from the proposed method from $4.36 \%$ to $9.23 \%$.

\section{Conclusions}

The results of the calculations show that in order to achieve the maximum traction force on the hook in terms of adhesion during the transition to the next higher traction class, it is necessary that the energy saturation of the tractor with the technological module corresponds to the energy saturation of the tractor to which the technological module is connected ( $1.59 \ldots 1.65 \mathrm{~kW} / \mathrm{kN})$, and the tractor itself, to which the technological module is connected, had an energy saturation $(2.0 \ldots 2.41 \mathrm{~kW} / \mathrm{kN})$. Thus, in the case of using the Belarus 82.1 tractor with TM, it is necessary to carry out a set of measures to increase the tractor engine power by $25 \mathrm{~kW}$.

\section{References}

1. Godzhaev Z.A., Beilis V.M., Shevtsov V.G., Lavrov A.V. Electrotechnology and electrical equipment in the agro-industrial complex. 4 (41). , 151-158 (2020).

2. Lavrov A.V., Sidorov M.V., Voronin V.A. Rural mechanic. 3, 5-7 (2021).

3. Lavrov A.V., Shevtsov V.G., Zubina V.A., Rusanov A.V. Rural mechanic. 3 (140), 57-66. (2020).

4. Initial requirements for basic machine technological operations in crop production: [collection] / Ministry of villages. households Ros. Federation, Feder. village agency. host; [developer. : V. P. Elizarov and others]. - M .: Rosinformagrotech, 2005 (Type. FGNU Rosinformagrotech).- 270 p.

5. Lavrov A., Shevtsov V., Sidorov M. E3S Web of Conferences, 3 (140), 2019.

6. Sidorov M.V., Lavrov A.V., Voronin V.A. Electrotechnology and electrical equipment in the agro-industrial complex. 4(37)., p. 57-62 (2019). 
7. Sidorov M.V. Increasing the efficiency of using a machine-tractor unit due to the use of a technological module with driving wheels for a tractor of traction class 1.4 Voronezh, 2016. .

8. Kutkov G.M. Tractors and agricultural machines. 12, 3-9(1989).

9. Sidorov V.N., Loktik O.V., Sidorov M.V. Design, use and reliability of agricultural machines. 1 (1), 112-115 (2002).

10. Sidorov V.N., Sidorov M.V., Kutkov G.M. journal: science, technology and education. 2 (6)., 37-46 (2016). 